\title{
PENGARUH STRES KERJA TERHADAP KINERJA KARYAWAN DIMEDIASI OLEH KEPUASAN KERJA KARYAWAN KOPERASI GRAHA CANTI SEMAWANG-SANUR
}

\author{
I Wayan Bayu Sandiartha ${ }^{1}$ \\ I Gusti Made Suwandana ${ }^{2}$ \\ ${ }^{1,2}$ Fakultas Ekonomi dan Bisnis Universitas Udayana (Unud), Bali, Indonesia \\ email: bayusandiartha@gmail.com
}

\begin{abstract}
ABSTRAK
Penelitian ini ditujukan untuk menguji secara empiris pengaruh stress kerja terhadap kepuasan kerja, pengaruh stress kerja terhadap kinerja karyawan, pengaruh kepuasan kerja terhadap kinerja karyawan dan pengaruh kepuasan kerja memediasi stress kerja terhadap kinerja karyawan. Pengambilan sampel dalam penelitian ini menggunakan teknik sampel jenuh atau sensus, sehingga jumlah sampel penelitian sebanyak 42 orang karyawan. Populasi dalam penelitian ini adalah seluruh karyawan tetap pada Koperasi Graha Canti Semawang Sanur. Data dikumpulkan menggunakan kuesioner kemudian dianalisis menggunakan teknik analisis jalur (Path Analysis). Hasil penelitian menunjukkan bahwa stress kerja berpengaruh negatif dan signfikan terhadap kepuasan kerja dan kinerja karyawan, kepuasan kerja berpengaruh positif dan signifikan terhadap kinerja karyawan, kepuasan kerja secara positif dan signifikan memediasi pengaruh stress kerja terhadap kinerja karyawan. Ketika stress kerja yang dirasakan karyawan rendah maka dapat meningkatkan kepuasan kerja, sehingga kinerja karyawan akan semakin meningkat.
\end{abstract}

Kata Kunci: Stress Kerja, Kinerja Karyawan, Kepuasan Kerja.

\begin{abstract}
This study aimed to empirically examine the effect of job stress on job satisfaction, the effect of job stress on employee performance, the effect of job satisfaction on employee performance and the effect of job satisfaction mediating work stress on employee performance. Sampling in this study used a saturated or census sample technique, so the number of research samples was 42 employees. The population in this study were all permanent employees at the Graha Canti Semawang Cooperative in Sanur. Data were collected using a questionnaire and then analyzed using path analysis techniques (Path Analysis). The results showed that job stress has a negative and significant effect on job satisfaction and employee performance, job satisfaction has a positive and significant effect on employee performance, job satisfaction positively and significantly mediates the effect of work stress on employee performance. When work stress felt by employees is low, it can increase job satisfaction, so employee performance will increase.
\end{abstract}

Keywords: Job Stress, Employee Performance, Job Satisfaction. 


\section{PENDAHULUAN}

Pentingnya pengelolaan sumber daya manusia yang berkualitas dan kompetitif merupakan elemen terpenting yang seringkali menjadi penentu eksistensi perusahaan tempatnya bernaung, akan tetapi sumber daya manusia dalam organisasi penuh dengan keterbatasan dalam melaksanakan tugas yang diembannya. Beberapa permasalahan pada kesadaran akan tugas dan tanggung jawab individu terhadap tugas pokok dan fungsi dari masing-masing individu dalam organisasi, sehingga haruslah ada upaya dari organisasi untuk meningkatkan kinerja karyawan untuk mencapai tujuan organisasi.

Salah satu masalah yang dihadapi Koperasi Graha Canti saat ini adalah kinerja yang belum maksimal. Kinerja karyawan adalah bagian terpenting didalam suatu perusahaan, maka dari itu perusahaan sangat perlu memperhatikan kebutuhan karyawan dalam bekerja sehingga nantinya kinerja karyawan akan meningkat atau menjadi lebih baik. Kinerja merefleksikan seberapa baik karyawan memenuhi persyaratan sebuah pekerjaan. Faktor-faktor yang mempengaruhi kinerja karyawan adalah kepuasan kerja, komitemen organisasional, motivasi, leader member exchange atau kepemimpinan, pendidikan, disiplin kerja, ketrampilan, sikap etika kerja, gizi dan kesehatan, tingkat gaji, lingkungan kerja dan iklim kerja, teknologi, sarana produksi, jaminan sosial, manajemen, dan kesempatan promosi jabatan. Salah satu faktor yang mempengaruhi kinerja karyawan adalah kepuasan kerja karyawan. Pada kondisi sebenarnya di Koperasi Graha Canti terdapat masalah yaitu tingkat kehadiran karyawan yang dapat mempengaruhi kinerja Koperasi secara keseluruhan untuk mencapai suatu target yang ditentukan. Berikut adalah tingkat absensi karyawan Koperasi Graha Canti yang dapat dilihat pada Tabel 1. berikut ini.

Tabel 1.

Tingkat Absensi Karyawan Koperasi Graha Canti Bulan April - Agustus Tahun 2019

\begin{tabular}{crrrrr}
\hline Bulan & $\begin{array}{c}\text { Jumlah } \\
\text { Pegawai }\end{array}$ & $\begin{array}{c}\text { Jumlah } \\
\text { Hari Kerja } \\
\text { Efektif }\end{array}$ & $\begin{array}{c}\text { Total Hari Kerja } \\
\text { Efektif/ Bulan }\end{array}$ & $\begin{array}{c}\text { Total } \\
\text { Absensi }\end{array}$ & $\begin{array}{c}\text { Persentase } \\
\text { Tingkat Absensi } \\
(\%)\end{array}$ \\
\hline April & 42 & 26 & 1.092 & 120 & 10,9 \\
Mei & 42 & 26 & 1.092 & 105 & 9,6 \\
Juni & 42 & 26 & 1.092 & 95 & 8,6 \\
Juli & 42 & 24 & 1.008 & 150 & 14,8 \\
Agustus & 42 & 24 & 1.008 & 80 & 7,9 \\
\hline
\end{tabular}

Sumber: Koperasi Graha Canti, 2019

Dilihat dari Tabel 1. pada jumlah persentase tingkat absensi karyawan Koperasi Graha Canti masih dianggap kurang baik. Banyak faktor yang menyebabkan karyawan tidak masuk kerja, seperti sakit, upacara agama, ijin, dan tanpa keterangan. Dengan banyaknya karyawan yang tidak hadir membuat pekerjaan yang harus diselesaikan menjadi tertunda. Selain itu masih banyak karyawan yang tidak bersedia untuk bekerja lembur, melihat keadaan seperti ini sepatutnya dengan adanya lembur maka pekerjaan lebih cepat terselesaikan. 
Berdasarkan hasil wawancara dengan manajer Koperasi Graha Canti, selain absensi juga terdapat beberapa indikator rendahnya kinerja karyawan Koperasi Graha Canti yang disajikan pada Tabel 2. sebagai berikut.

Tabel 2.

Indikator Rendahnya Kinerja Karyawan Koperasi Graha Canti

\begin{tabular}{cl}
\hline Indikator Kinerja & \multicolumn{1}{c}{ Faktor Kinerja Rendah } \\
\hline Kualitas Kerja & $\begin{array}{l}\text { Masih terdapat karyawan yang bermalas-malasan dalam } \\
\text { mengerjakan pekerjaannya }\end{array}$ \\
Kehadiran dan Ketepatan Waktu & $\begin{array}{l}\text { Masih ada karyawan yang hadirnya tidak tepat waktu } \\
\text { Inisiatif }\end{array}$ \\
Kurangnya tanggungjawab dari karyawan dalam \\
menyelesaikan tugas-tugasnya. \\
Masih adanya komunikasi yang buruk antara karyawan satu \\
Tekanan atau Stress & $\begin{array}{l}\text { Masih adanya karyawan yang merasa tertekan dan jenuh } \\
\text { saat bekerja }\end{array}$ \\
\hline
\end{tabular}

Sumber: Koperasi Graha Canti, 2019

Dari lima indikator, tekanan atau stress kerja yang paling banyak dialami oleh karyawan Koperasi Graha Canti. Tekanan yang dialami karyawan berasal dari target nasabah yang harus dicapai setiap karyawannya yaitu sebanyak 70 orang. Tetapi rata-rata karyawan hanya mampu mencapai 20 sampai 30 orang saja per harinya. Tentu saja itu berpengaruh pada kompensasi dan bonus yang didapat karyawan, jika tidak sesuai target maka bonus yang didapat tidak akan sesuai.

Tulhusnah et al. (2018) mengemukakan karyawan yang kurang mendapatkan kepuasan kerja cenderung lebih sering absen. Menurut hasil wawancara terhadap manajer Koperasi Graha Canti bahwa masih banyak terdapat karyawan yang hadir tidak tepat waktu saat bekerja, oleh karena itu kejadian ini harus menjadi perhatian serius bagi pihak manajemen karena jika kejadian ini dibiarkan terus menerus maka tidak menutup kemungkinan akan terjadi peningkatan kejadian serupa yang nantinya akan bisa berdampak pada kinerja perusahaan secara keseluruhan. Pihak manajemen harus mempertimbangkan kebijakan yang tepat digunakan untuk menindak lanjutin kejadian ini, seperti pemberian teguran secara langsung, pemberian peringatan, dan pemberian sanksi yang dapat dijadikan pilihan untuk dipertimbangkan. Selain itu, karyawan juga merasa tidak puas dengan kompensasi yang mereka terima karena merasa tidak sesuai dengan kontribusi yang mereka berikan, sehinggga berdampak pada stress kerja karyawan yang tentunya dapat menyebabkan kinerja mereka semakin menurun.

Beberapa hasil penelitian menjelaskan bahwa terdapat pengaruh antara kinerja karyawan, stress kerja dan kepuasan kerja. Kasim (2016) menyatakan bahwa stress kerja berpengaruh negatif terhadap kinerja karyawan, karena beban kerja yang berlebihan, pengembangan karier, masalah keluarga dan masalah organisasi dapat menurunkan kinerja karyawan tersebut dimana karyawan merasa capek, gelisah, tidak bahagia, sakit kepala, lemah serta mudah marah. Wijaya \& Sudibya (2014) menyatakan bahwa stress kerja berpengaruh negatif signifikan terhadap kinerja karyawan. Penelitian yang dilakukan Zafar et al. (2015) menyatakan hal yang bertolak belakang dengan penelitian tersebut, dengan hasil 
yang menyatakan bahwa terdapat hubungan positif signifikan antara stress kerja terhadap kinerja karyawan.

Huda (2018) menyatakan stress kerja merupakan masalah serius yang berhubungan dengan kepuasan kerja, hal ini dibuktikan dengan penelitian yang telah dilakukan memperoleh hasil bahwa stress kerja berpengaruh negatif terhadap kepuasan kerja. Beberapa penelitian mengemukakan bahwa kepuasan kerja memiliki pengaruh positif dan signifikan terhadap kinerja karyawan yang berarti bahwa rasa kepuasan kerja yang dimiliki pekerja membuat pekerja untuk meningkatkan kinerjanya. Prawira \& Suwandana (2019) yang menemukan stress kerja memiliki pengaruh negatif terhadap kepuasan kerja. Berdasarkan hasil penelitian Diputra \& Surya (2018) didapatkan hasil bahwa kepuasan kerja berpengaruh positif antara variabel stress kerja terhadap kinerja karyawan melalui variabel kepuasan kerja.

Stress dapat mempengaruhi kinerja karyawan. Yuen et al. (2013) menyatakan bahwa terdapat pengaruh negatif antara stress kerja terhadap kinerja karyawan. Zafar et al. (2015) menyatakan bahwa terdapat hubungan positif signifikan antara stress kerja terhadap kinerja karyawan. Stress adalah suatu kondisi dinamis dimana seorang individu diharapkan pada peluang, tuntutan, atau sumber daya yang terkait dengan apa yang diharuskan oleh individu itu dan hasilnya dipandang tidak pasti dan penting, stress sendiri tidak mesti buruk meskipun biasanya dibahas dalam konteks negatif stress juga memiliki nilai positif, dari sudut pandang organisasi manajemen mungkin tidak peduli ketika karyawan mengalami tingkat stress rendah hingga menengah (Robbins \& Judge, 2011). Stress juga merupakan kondisi yang menjadi komponen yang berbeda termasuk tekanan emosional, khawatir, dan hilangnya keterlibatan dalam melaksanakan tugas.

Rivai (2005) mendefinisikan bahwa stress kerja merupakan suatu kondisi dimana timbulnya ketegangan fisik dan juga pikiran yang menyebabkan terjadinya kondisi yang tidak seimbang dan sangat memengaruhi kinerja karyawan. Stress kerja merupakan suatu gejala atau perasaan yang dapat timbul dalam diri seorang pekerja dan dapat memberikan dampak dalam suatu organisasi atau perusahaan, yang akan memberikan pengaruh terhadap kepuasan karyawan dan akan mempengaruhi kinerja karyawan. Stress kerja meningkat maka akan menyebabkan timbulnya keinginan keluar yang ada pada diri karyawan (Chandio et al., 2013). Stress kerja akan menimbulkan biaya yang signifikan dalam hal produktivitas yang rendah, karyawan yang sakit dan waktu yang hilang (Kouloubandi, 2012). Stress kerja pada karyawan apabila ditunjang dengan kepuasan kerja yang tinggi maka kinerja karyawan akan maksimal dalam bekerja (Adawiyah, 2015).

Penelitian ini ditujukan untuk menguji secara empiris pengaruh stress kerja terhadap kepuasan kerja, pengaruh stress kerja terhadap kinerja karyawan, pengaruh kepuasan kerja terhadap kinerja karyawan dan pengaruh kepuasan kerja memediasi stress kerja terhadap kinerja karyawan.

Teori pertukaran sosial (social exchange theory) adalah teori yang paling penting untuk memahami perilaku seseorang di tempat kerja. (Serim et al., 2014) mengemukakan bahwa hubungan di tempat kerja memiliki unsur-unsur dari teori 
pertukaran sosial. Komponen utama dari teori pertukaran sosial yang melibatkan persepsi terhadap kualitas interaksi atasan-bawahan dan persepsi terhadap dukungan organisasional dalam hal ini adalah hukum timbal balik yaitu bahwa ketika individu diperlukan dengan baik oleh orang lain akan muncul perasaan kewajiban bagi individu tersebut untuk membalasnya dengan perlakuan yang baik pula (Blau, 2017).

Seorang pemimpin perusahaan yang mengetahui keinginan karyawan dan dapat menjelaskan apa yang akan diperoleh jika hasil kerjanya sesuai dengan harapan seperti memberikan imbalan yang sebanding dengan kinerjanya, maka karyawan akan berusaha untuk menunjukan kinerjanya yang baik secara maksimal. Teori ini menjelaskan ketika pemimpin mengetahui apa yang masingmasing karyawan butuhkan dalam mencapai kinerja maksimal. Nawaz et al., (2014) menyatakan bahwa ketika organisasi mengurus karyawan, maka ada hubungan pertukaran sosial yang menjanjikan untuk meningkatkan kinerja.

Stress individu sangat mempengaruhi organisasi dalam mencapai tujuannya. Stress individu mungkin yang paling berpengaruh terhadap semua stresssor yang ada karena merupakan perubahan yang tak pernah berhenti, dan merupakan bagian dari kehidupan saat ini (Rivai, 2005). Purbaningrat Yo \& Surya (2015) mengemukakan bahwa stresss kerja merupakan masalah serius yang berhubungan dengan kepuasan kerja, hal ini dibuktikan dengan penelitian yang telah dilakukan memperoleh hasil bahwa stress kerja berpengaruh negatif terhadap kepuasan kerja. Hal ini didukung juga oleh penelitian yang dilakukan Redita \& Dewi (2019) menemukan stresss kerja berpengaruh terhadap kepuasan kerja, didukung oleh penelitian yang dilakukan Prawira \& Suwandana (2019) yang menemukan stresss kerja memiliki pengaruh negatif terhadap kepuasan kerja. Penelitian yang dilakukan oleh (Singh dan Nayak, 2017) kepada polisi di India menemukan bahwa stresss kerja berpengaruh secara signifikan terhadap kepuasan kerja.

$\mathrm{H}_{1}$ : Stress kerja berpengaruh negatif terhadap kepuasan kerja.

Hasil penelitian Wijaya \& Sudibya (2014) menyatakan bahwa stress kerja berpengaruh negatif signifikan terhadap kinerja karyawan, karena beban kerja yang berlebihan, pengembangan karier, masalah keluarga dan masalah organisasi dapat menurunkan kinerja karyawan tersebut dimana karyawan merasa capek, gelisah, tidak bahagia, sakit kepala, lemah serta mudah marah. Prawira \& Suwandana (2019) juga mengungkap terdapat hubungan negatif signifikan antara variabel stress kerja dan kinerja karyawan. Namun penelitian tersebut bertolak belakang dengan penelitian dilakukan oleh Zafar et al. (2015) yang menyebutkan bahwa stress kerja berpengaruh positif terhadap kinerja karyawan. Diputra \& Surya (2018) menunjukan bahwa stress kerja berpengaruh negatif dan signifikan terhadap kepuasan kerja dan kinerja karyawan. Menurut penelitian Sri \& Karini (2015) terdapat hubungan yang negatif antara stress kerja dengan kinerja, hal ini berarti karyawan yang tingkat stress nya rendah akan memiliki kinerja yang lebih tinggi dibandingkan dengan karyawan yang memiliki tingkat stress yang lebih tinggi.

$\mathrm{H}_{2}$ : Stress kerja berpengaruh negatif terhadap kinerja karyawan.

Penelitian dari Hermawan \& Suwandana (2019) menyatakan bahwa kepuasan berpengaruh positif terhadap kinerja karyawan. Zafar et al. (2015) 
menunjukan kepuasan kerja berpengaruh terhadap kinerja. Hal ini berpengaruh secara langsung, namun memiliki hubungan yang signifikan akan karena hasil riset menunjukan hasil positif. Diputra \& Surya (2018) menyatakan bahwa kepuasan kerja memberikan pengaruh terhadap kinerja karyawan yang signifikan. Ini mengindikasikan bahwa kepuasan kerja mampu memberi kontribusi kepada peningkatan kinerja karyawan. Prawira \& Suwandana (2019) juga mengungkapkan bahwa kepuasan kerja secara signifikan memiliki hubungan dengan kinerja karyawan. Beberapa penelitian mengemukakan bahwa kepuasan kerja memiliki pengaruh positif dan signifikan terhadap kinerja karyawan yang berarti bahwa rasa kepuasan kerja yang dimiliki pekerja membuat pekerja untuk meningkatkan kinerjanya.

$\mathrm{H}_{3}$ : Kepuasan berpengaruh positif terhadap kinerja karyawan.

Berdasarkan hasil penelitian Diputra \& Surya (2018) didapatkan hasil bahwa kepuasan kerja berpengaruh positif antara variabel stresss kerja terhadap kinerja karyawan melalui variabel kepuasan kerja. Prawira \& Suwandana (2019) menyatakan bahwa terdapat hasil kepuasan kerja sebagai pemediasi antara stress kerja terhadap kinerja karyawan. Adawiyah (2015) menemukan bahwa kepuasan kerja berpengaruh positif dan signifikan dalam memediasi stress kerja terhadap kinerja karyawan. Hasil penelitian Manurung dan Ratnawati (2012) juga menunjukkan bahwa kepuasan kerja mampu memediasi pengaruh stress kerja terhadap kinerja karyawan.

$\mathrm{H}_{4}$ : Kepuasan kerja memediasi stress kerja terhadap kinerja karyawan.

\section{METODE PENELITIAN}

Penelitian ini termasuk dalam penelitian yang bersifat asosiatif. Penelitian dilakukan di Koperasi Graha Canti Jl. Danau Poso No. 1 A, Banjar Semawang Sanur. Alasan peneliti memilih lokasi ini sebagai obyek penelitian yaitu karena adanya indikasi masalah rendahnya kepuasan kerja karyawan di Koperasi Graha Canti yang menyebabkan kinerja karyawan menjadi menurun. Objek penelitian ini adalah stress kerja, kinerja dan kepuasan kerja pada Koperasi Graha Canti Denpasar, Bali. Variabel endogen yang digunakan yakni kepuasan kerja (M) dan kinerja karyawan (Y). Sementara variabel eksogen yakni stress kerja (X). Dalam penelitian ini juga terdapat variabel eksogen endogen yakni kepuasan kerja(M).

Kinerja dalam diukur berdasarkan indikator yang dikemukakan dalam penelitian Cahyono (2014) yang meliputi pencapaian jumlah pekerjaan sesuai target, pengerjaan tugas dan pekerjaan dengan cermat dan teliti, pekerjaan rapi dan mudah dipertanggungjawabkan, tingkat ketidaksamaan dalam bekerja, optimalisasi jam kerja, dan pengerjaan tugas sesuai dengan kualitas yang ditargetkan serta ketepatan waktu kerja.

Indikator stress kerja menurut penelitian Dewi \& Wibawa (2016) yang meliputi merasa takut apabila ada perubahan sistem yang baru, merasa tidak senang apabila terjadi konflik antar kelompok, merasa tidak senang apabila kinerja tidak sesuai dengan pekerjaan yang tidak memadai, merasa bingung ketika memiliki dua persen pekerjaan yang berbeda dalam bekerja, merasa jenuh apabila kualitas supervisi jelek, merasa emosi apabila mendapat beban kerja yang 
berlebihan, merasa tergesa-gesa ketika ada desakan waktu untuk menyelesaikan tugas, merasa menyerah apabila frustasi karena pekerjaan yang dikerjakan tidak sesuai dengan harapan.

Indikator yang digunakan dalam mengukur kepuasan kerja karyawan dalam perusahaan menurut Alshitri (2013) adalah promosi, gaji, prosedur, rekan kerja dan suvervisi. Sumber data primer dalam penelitian ini adalah responden yang merupakan karyawan Koperasi Graha Canti. Sumber data sekunder dalam penelitian ini adalah dokumentasi perusahaan Koperasi Graha Canti. Penelitian ini menggunakan teknik analisis jalur atau path analysis. Adapun persamaan Substruktural 1 dijabarkan sebagai berikut.

$$
\mathrm{M}=\beta_{1} \mathrm{X}_{1}+\mathrm{e}_{1}
$$

Sementara persamaan sub-struktural 2 dijabarkan sebagai berikut.

$$
\mathrm{Y}=\beta_{1} \mathrm{X}_{2}+\beta_{1} \mathrm{M}+\varepsilon_{2}
$$

Keterangan:

$$
\begin{array}{ll}
\mathrm{X} & =\text { stress kerja } \\
\mathrm{M} & =\text { kepuasan kerja } \\
\mathrm{Y} & =\text { kinerja karyawan } \\
\beta_{1-} \beta_{2} & =\text { Koefisien regresi variabel } \\
\varepsilon & =\text { error }
\end{array}
$$

\section{HASIL DAN PEMBAHASAN}

Karakteristik responden merupakan data responden yang dikumpulkan untuk mengetahui profil responden penelitian. Penelitian ini menggunakan sampel 42 Karyawan. Berikut data identitas responden berdasarkan umur, jenis kelamin, pendidikan terakhir, masa kerja dan posisi reponden. Secara rinci karakteristik dijabarkan sebagai berikut.

Berdasarkan hasil analisis karakteristik responden berdasarkan umur diperoleh hasil yang dijabarkan sebagai berikut.

Tabel 3.

Karakteristik Responden Menurut Umur

\begin{tabular}{cccc}
\hline No & Umur (Tahun) & Jumlah (Orang) & Jumlah (Persentase \\
\hline 1 & $21-25$ Tahun & 8 & \%) \\
2 & 26 - 30 Tahun & 19 & 45,0 \\
3 & 31 - 35 Tahun & 9 & 21,4 \\
4 & $>$ 35 Tahun & 6 & 14,3 \\
& Jumlah & $\mathbf{4 2}$ & $\mathbf{1 0 0}$ \\
\hline
\end{tabular}

Sumber: Data primer diolah, 2019

Pada Tabel 3. dapat dilihat responden dengan umur dari 26 - 30 tahun yang paling mendominasi diantara umur lainnya yakni 19 orang atau $45,2 \%$. Sedangkan responden dengan umur $>35$ tahun yang paling sedikit yakni 6 orang atau 14,3\%. Berdasarkan hasil analisis karakteristik responden berdasarkan jenis kelamin diperoleh hasil yang dijabarkan sebagai berikut.

Pada Tabel 4. dapat dilihat responden dengan jenis kelamin perempuan lebih mendominasi yakni 29 orang atau 69\%. Sedangkan responden dengan jenis 
kelamin laki-laki sebanyak 13 orang atau 31\%. Berdasarkan hasil analisis karakteristik responden berdasarkan pendidikan terakhir, diperoleh hasil yang dijabarkan sebagai berikut.

Tabel 4.

Karakteristik Responden Menurut Jenis Kelamin

\begin{tabular}{cccc}
\hline No & Jenis Kelamin & Jumlah (Orang) & Jumlah (Persentase \\
& Laki - Laki & 13 & 31,0 \\
2 & Perempuan & 29 & 69,0 \\
& Jumlah & $\mathbf{4 2}$ & $\mathbf{1 0 0}$ \\
\hline
\end{tabular}

Sumber: Data primer diolah, 2019

Pada Tabel 5. dapat dilihat responden dengan pendidikan terakhir S1 yang paling mendominasi diantara pendidikan lainnya yakni 20 orang atau 47,6\%. Sedangkan responden yang paling sedikit adalah responden dengan pendidikan terakhir lulus Diploma yakni 10 orang atau $23,8 \%$.

Tabel 5.

Karakteristik Responden Menurut Pendidikan Terakhir

\begin{tabular}{cccc}
\hline \multirow{2}{*}{ No } & Pendidikan Terakhir & Jumlah (Orang) & $\begin{array}{c}\text { Jumlah (Persentase } \\
\text { \%) }\end{array}$ \\
\hline 1 & SMA/K & 12 & 28,6 \\
2 & Diploma & 10 & 23,8 \\
3 & S1 & 20 & 47,6 \\
& Jumlah & $\mathbf{4 2}$ & $\mathbf{1 0 0}$ \\
\hline
\end{tabular}

Sumber: Data primer diolah, 2019

Berdasarkan hasil analisis karakteristik responden berdasarkan masa kerja diperoleh hasil yang dijabarkan sebagai berikut.

Tabel 6.

Karakteristik Responden Menurut Masa Kerja

\begin{tabular}{cccc}
\hline No & Lama Masa Kerja & Jumlah (Orang) & Jumlah (Persentase \\
\hline 1 & 1 - 2 Tahun & 10 & \%) \\
2 & 3 - 5 Tahun & 24 & 57,1 \\
3 & $>$ 5 Tahun & 8 & 19,0 \\
& Jumlah & 42 & 100 \\
\hline
\end{tabular}

Sumber: Data primer diolah, 2019

Pada Tabel 6. dapat dilihat responden dengan masa kerja 3 - 5 tahun yang paling mendominasi diantara masa kerja yang lainnya yakni 24 orang atau 57,1\%. Sedangkan responden yang paling sedikit adalah responden dengan masa kerja > 5 tahun yakni 8 orang atau 19,0\%.

Berdasarkan hasil analisis karakteristik responden berdasarkan posisi diperoleh hasil yang dijabarkan sebagai berikut. Pada Tabel 7. dapat dilihat responden dengan posisi kolektor yang paling mendominasi diantara posisi yang 
lainnya yakni 15 orang atau 35,7\%. Sedangkan responden yang paling sedikit terdapat 16 posisi yang memiliki nilai yang sama yaitu $2,4 \%$.

Tabel 7.

Karakteristik Responden Menurut Posisi

\begin{tabular}{cccc}
\hline No & Lama Posisi & Jumlah (Orang) & Jumlah (Persentase) \\
\hline 1 & Kabag Kredit & 1 & 2.4 \\
2 & Kasi Kredit & 1 & 2,4 \\
3 & Analisis Kredit & 1 & 2,4 \\
4 & Staf/ Admin Kredit & 1 & 2,4 \\
5 & Account Officer & 1 & 2,4 \\
6 & Kabag Dana & 1 & 2,4 \\
7 & Admin Dana & 1 & 2,4 \\
8 & Kolektor & 5 & 32,7 \\
9 & Kasi Pelayanan Kas & 3 & 11,9 \\
10 & Teller & 1 & 7,1 \\
11 & Kepala Unit Perdagangan & 4 & 2,4 \\
12 & Bagian Pelayanan/ Kasir & 1 & 9,5 \\
13 & Manajer & 1 & 2,4 \\
14 & Kabag Personalia & 3 & 2,4 \\
15 & Satpam & 2 & 7,1 \\
16 & Cleaning Service & $\mathbf{4 2}$ & 4,8 \\
\hline \multicolumn{4}{c}{ Jumlah } \\
\hline
\end{tabular}

Sumber: Data primer diolah, 2019

Ketentuan instrumen dapat dikatakan valid apabila korelasi tiap faktor sama dengan 0,30 atau lebih maka faktor tersebut merupakan construct yang kuat.

Tabel 8.

Rekapitulasi Hasil Uji Validitas Instrumen Penelitian

\begin{tabular}{ccccc}
\hline \multirow{2}{*}{ Variabel } & Indikator & $\begin{array}{c}\text { Koefisien } \\
\text { Korelasi }\end{array}$ & $\begin{array}{c}\text { Koefisien } \\
\text { Batas }\end{array}$ & Keterangan \\
\hline \multirow{2}{*}{ Stress Kerja (X) } & $\mathrm{X}_{.1}$ & 0,819 & 0,3 & Valid \\
& $\mathrm{X}_{.2}$ & 0,826 & 0,3 & Valid \\
& $\mathrm{X}_{.3}$ & 0,880 & 0,3 & Valid \\
& $\mathrm{X}_{.4}$ & 0,827 & 0,3 & Valid \\
& $\mathrm{X}_{.5}$ & 0,851 & 0,3 & Valid \\
& $\mathrm{X}_{.6}$ & 0,856 & 0,3 & Valid \\
& $\mathrm{X}_{.7}$ & 0,796 & 0,3 & Valid \\
& $\mathrm{X}_{.8}$ & 0,812 & 0,3 & Valid \\
& $\mathrm{M}_{.1}$ & 0,864 & 0,3 & Valid \\
& $\mathrm{M}_{.2}$ & 0,826 & 0,3 & Valid \\
& $\mathrm{M}_{.3}$ & 0,859 & 0,3 & Valid \\
& $\mathrm{M}_{.4}$ & 0,828 & 0,3 & Valid \\
& $\mathrm{M}_{.5}$ & 0,803 & 0,3 & Valid \\
& $\mathrm{Y}_{.1}$ & 0,815 & 0,3 & Valid \\
& $\mathrm{Y} .2$ & 0,792 & 0,3 & Valid \\
\hline
\end{tabular}

Bersambung... 


\begin{tabular}{ccccc}
\hline Variabel & Indikator & $\begin{array}{c}\text { Koefisien } \\
\text { Korelasi }\end{array}$ & $\begin{array}{c}\text { Koefisien } \\
\text { Batas }\end{array}$ & Keterangan \\
\hline Y.3 & 0,904 & 0,3 & Valid \\
Y.4 & 0,875 & 0,3 & Valid \\
Y.5 & 0,789 & 0,3 & Valid \\
Y.6 & 0,863 & 0,3 & Valid \\
Y.7 & 0,815 & 0,3 & Valid \\
\hline
\end{tabular}

Sumber: Data primer diolah, 2019

Hasil uji validitas pada Tabel 8. menunjukkan bahwa seluruh instrumen penelitian yang digunakan untuk mengukur variabel Stress Kerja, Kepuasan Kerja dan Kinerja Karyawan memiliki nilai koefisien korelasi dengan skor total seluruh item pernyataan lebih besar dari 0,3 . Hal ini menunjukkan bahwa butir-butir pernyataan dalam instrument penelitian tersebut valid dan layak digunakan sebagai instrument penelitian.

Tabel 9.

Rekapitulasi Hasil Uji Reliabilitas Instrumen Penelitian

\begin{tabular}{|c|c|c|c|}
\hline No. & Variabel & $\begin{array}{c}\text { Cronbach's } \\
\text { Alpha }\end{array}$ & Keterangan \\
\hline 1 & Stresss Kerja (X) & 0,937 & Reliabel \\
\hline 3 & Kepuasan Kerja (M) & 0,892 & Reliabel \\
\hline 4 & Kinerja Karyawan (Y) & 0,925 & Reliabel \\
\hline
\end{tabular}

Sumber: Data primer diolah, 2019

Hasil uji reliabilitas yang disajikan dalam Tabel 9. menunjukkan bahwa seluruh instrumen penelitian memiliki koefisien Cronbach's Alpha lebih dari 0,60 . Jadi dapat dinyatakan bahwa seluruh variabel telah memenuhi syarat reliabilitas atau kehandalan sehingga dapat digunakan untuk melakukan penelitian.

Tabel 10.

Deskripsi Jawaban Responden Terhadap Stress Kerja

\begin{tabular}{|c|c|c|c|c|c|c|c|c|}
\hline \multirow[t]{2}{*}{ No } & \multirow[t]{2}{*}{ Pernyataan } & \multicolumn{5}{|c|}{$\begin{array}{c}\text { Frekuensi Jawaban } \\
\text { Responden }\end{array}$} & \multirow{2}{*}{$\begin{array}{l}\text { Rata- } \\
\text { Rata }\end{array}$} & \multirow[t]{2}{*}{ Kriteria } \\
\hline & & STS & TS & $\mathbf{N}$ & $\mathbf{S}$ & SS & & \\
\hline 1 & $\begin{array}{l}\text { Saya merasa takut apabila ada } \\
\text { berbagai bentuk perubahan } \\
\text { sistem yang baru di perusahaan }\end{array}$ & 0 & 5 & 26 & 8 & 3 & 3,21 & Cukup \\
\hline 2 & $\begin{array}{l}\text { Saya merasa tidak senang apabila } \\
\text { terjadi konflik antar kelompok } \\
\text { saat bekerja di dalam perusahaan }\end{array}$ & 0 & 6 & 23 & 11 & 2 & 3,21 & Cukup \\
\hline 3 & $\begin{array}{l}\text { Saya merasa tidak senang apabila } \\
\text { pelaksanaan kinerja tidak sesuai } \\
\text { dengan pekerjaan di dalam } \\
\text { perusahaan yang tidak memadai }\end{array}$ & 0 & 9 & 21 & 10 & 2 & 3,12 & Cukup \\
\hline 4 & $\begin{array}{l}\text { Saya merasa bingung ketika } \\
\text { memiliki dua peran pekerjaan } \\
\text { yang berbeda dalam bekerja }\end{array}$ & 1 & 9 & 21 & 11 & 0 & 3,00 & Cukup \\
\hline
\end{tabular}


Lanjutan Tabel 10.

\begin{tabular}{|c|c|c|c|c|c|c|c|c|}
\hline \multirow[t]{2}{*}{ No } & \multirow{2}{*}{ Pernyataan } & \multicolumn{5}{|c|}{$\begin{array}{c}\text { Frekuensi Jawaban } \\
\text { Responden }\end{array}$} & \multirow{2}{*}{$\begin{array}{l}\text { Rata- } \\
\text { Rata }\end{array}$} & \multirow{2}{*}{ Kriteria } \\
\hline & & STS & TS & $\mathbf{N}$ & $\mathbf{S}$ & SS & & \\
\hline 5 & $\begin{array}{l}\text { Saya merasa jenuh apabila } \\
\text { kualitas supervisi jelek }\end{array}$ & 0 & 9 & 20 & 13 & 0 & 3,10 & Cukup \\
\hline 6 & $\begin{array}{l}\text { Saya merasa emosi apabila } \\
\text { mendapat beban kerja yang } \\
\text { berlebihan }\end{array}$ & 0 & 12 & 15 & 15 & 0 & 3,07 & Cukup \\
\hline 7 & $\begin{array}{l}\text { Saya merasa tergesa-gesa ketika } \\
\text { ada desakan waktu untuk } \\
\text { menyelesaikan tugas kantor }\end{array}$ & 0 & 9 & 25 & 7 & 1 & 3,00 & Cukup \\
\hline 8 & $\begin{array}{l}\text { Saya merasa menyerah apabila } \\
\text { saya frustasi saat pekerjaan yang } \\
\text { saya kerjakan tidak sesuai dengan } \\
\text { harapan }\end{array}$ & 1 & 14 & 20 & 6 & 1 & 2,81 & Cukup \\
\hline & Rata-rata keseluruhan vat & els & $\mathrm{K}$ & & & & 3,07 & Cukup \\
\hline
\end{tabular}
Sumber: Data primer diolah, 2019

Tabel 10. menunjukkan stresss kerja secara keseluruhan cukup hal ini dapat dilihat dari keseluruhan rata-rata nilai stresss kerja yaitu 3,07. Nilai rata-rata tertinggi pada pernyataan "Saya merasa takut apabila ada berbagai bentuk perubahan sistem yang baru di perusahaan" dan "Saya merasa tidak senang apabila terjadi konflik antar kelompok saat bekerja di dalam perusahaan". Nilai rata-rata terendah terdapat pada pernyataan "Saya merasa menyerah apabila saya frustasi saat pekerjaan yang saya kerjakan tidak sesuai dengan harapan".

Variabel Kepuasan Kerja dalam penelitian ini merupakan variabel mediasi yang diukur dengan menggunakan 5 pernyataan yang berhubungan dengan kepuasan kerja. Secara rinci hasil penelitian mengenai persepsi responden terhadap variabel Kepuasan Kerja disajikan pada Tabel 11.

Tabel 11.

Deskripsi Jawaban Responden Terhadap Variabel Kepuasan Kerja

\begin{tabular}{|c|c|c|c|c|c|c|c|c|}
\hline \multirow{2}{*}{ No } & \multirow{2}{*}{ Pernyataan } & \multicolumn{5}{|c|}{ Frekuensi Jawaban Responden } & \multirow{2}{*}{$\begin{array}{l}\text { Rata- } \\
\text { Rata }\end{array}$} & \multirow{2}{*}{$\begin{array}{l}\text { Krit } \\
\text { eria }\end{array}$} \\
\hline & & STS & TS & $\mathbf{N}$ & $\mathbf{S}$ & SS & & \\
\hline 1 & $\begin{array}{l}\text { Kesempatan promosi yang } \\
\text { diberikan perusahaan terbuka } \\
\text { lebar bagi semua karyawan } \\
\text { yang berprestasi }\end{array}$ & 1 & 4 & 12 & 14 & 11 & 3,71 & Puas \\
\hline 2 & $\begin{array}{l}\text { Saya merasa puas dengan gaji } \\
\text { yang saya terima karena sesuai } \\
\text { dengan kontribusi yang telah } \\
\text { saya berikan }\end{array}$ & 0 & 4 & 14 & 14 & 10 & 3,71 & Puas \\
\hline 3 & $\begin{array}{l}\text { Saya merasa puas dengan } \\
\text { kejelasan penerapan kebijakan } \\
\text { yang ditetapkan perusahaan }\end{array}$ & 0 & 4 & 17 & 11 & 10 & 3,64 & Puas \\
\hline 4 & $\begin{array}{l}\text { Saya merasa puas dengan } \\
\text { keharmonisan kerja yang } \\
\text { terjadi antara karyawan lainnya }\end{array}$ & 0 & 3 & 13 & 15 & 11 & 3,81 & Puas \\
\hline
\end{tabular}


Lanjutan Tabel 11.

\begin{tabular}{|c|c|c|c|c|c|c|c|c|}
\hline \multirow{2}{*}{ No } & \multirow{2}{*}{ Pernyataan } & \multicolumn{5}{|c|}{ Frekuensi Jawaban Responden } & \multirow{2}{*}{$\begin{array}{l}\text { Rata- } \\
\text { Rata }\end{array}$} & \multirow{2}{*}{$\begin{array}{l}\text { Krit } \\
\text { eria }\end{array}$} \\
\hline & & STS & TS & $\mathbf{N}$ & $\mathbf{S}$ & SS & & \\
\hline \multirow[t]{2}{*}{5} & $\begin{array}{l}\text { Pimpinan selalu membantu dan } \\
\text { memberi petunjuk mengenai } \\
\text { kegiatan sehari-hari sehingga } \\
\text { menimbulkan rasa puas dalam } \\
\text { diri saya }\end{array}$ & 0 & 7 & 15 & 13 & 7 & 3,48 & Puas \\
\hline & Rata-rata keseluruhan va & label Ke & uasa & Eerja & & & 3,67 & Puas \\
\hline
\end{tabular}

Tabel 10. menunjukkan secara keseluruhan rata-rata jawaban responden terhadap variabel kepuasan kerja memiliki nilai sebesar 3,67. Hasil penyebaran kuisioner menunjukkan bahwa pernyataan "Saya merasa puas dengan keharmonisan kerja yang terjadi antara karyawan lainnya" memiliki nilai rata-rata paling tinggi. Nilai rata-rata terendah terdapat pada pernyataan "Pimpinan selalu membantu dan memberi petunjuk mengenai kegiatan sehari-hari sehingga menimbulkan rasa puas dalam diri saya".

Kinerja Karyawan dalam penelitian ini merupakan variabel terikat yang diukur dengan menggunakan 7 pernyataan yang berhubungan dengan Kinerja Karyawan. Secara rinci hasil penelitian mengenai persepsi responden terhadap variabel Kinerja Karyawan disajikan pada Tabel 12. berikut.

Tabel 12.

Deskripsi Jawaban Responden Terhadap Variabel Kinerja Karyawan

\begin{tabular}{|c|c|c|c|c|c|c|c|c|}
\hline \multirow{2}{*}{ No } & \multirow{2}{*}{ Pernyataan } & \multicolumn{5}{|c|}{ FrekuensiJawaban Responden } & \multirow{2}{*}{$\begin{array}{l}\text { Rata- } \\
\text { Rata }\end{array}$} & \multirow{2}{*}{ Kriteria } \\
\hline & & STS & TS & $\mathbf{N}$ & $\mathbf{S}$ & SS & & \\
\hline 1 & $\begin{array}{l}\text { Saya mampu mencapai jumlah } \\
\text { pekerjaan sesuai dengan target } \\
\text { yang ditetapkan }\end{array}$ & 0 & 1 & 7 & 29 & 5 & 3,90 & Baik \\
\hline 2 & $\begin{array}{l}\text { Saya mengerjakan tugas } \\
\text { dengan teliti }\end{array}$ & 0 & 1 & 8 & 27 & 6 & 3,90 & Cukup \\
\hline 3 & $\begin{array}{l}\text { Saya mengerjakan pekerjaan } \\
\text { dengan rapi sehingga bisa } \\
\text { dipertanggung jawabkan }\end{array}$ & 0 & 1 & 10 & 22 & 9 & 3,93 & Baik \\
\hline 4 & $\begin{array}{l}\text { Saya dalam bekerja berusaha } \\
\text { untuk meminimalkan tingkat } \\
\text { kesalahan }\end{array}$ & 0 & 1 & 10 & 20 & 11 & 3,98 & Baik \\
\hline 5 & $\begin{array}{l}\text { Saya sangat optimal } \\
\text { menggunakan jam kerja }\end{array}$ & 0 & 1 & 19 & 11 & 11 & 3,76 & Baik \\
\hline 6 & $\begin{array}{l}\text { Saya mampu bekerja dengan } \\
\text { kualitas sesuai dengan target } \\
\text { yang ditetapkan }\end{array}$ & 0 & 3 & 4 & 22 & 13 & 4,07 & Baik \\
\hline 7 & $\begin{array}{l}\text { Saya menyelesaikan pekerjaan } \\
\text { dengan tepat waktu }\end{array}$ & 0 & 3 & 4 & 21 & 14 & 4,10 & Baik \\
\hline & Rata-rata keseluruhan var & bel Ki & rja K & Jaw & & & 3,95 & Baik \\
\hline
\end{tabular}

Tabel 12. menunjukkan secara keseluruhan rata-rata jawaban responden terhadap variabel Kinerja Karyawan memiliki nilai sebesar 3,95. Hasil penyebaran 
kuisioner menunjukkan bahwa Kinerja Karyawan perusahaan baik. Nilai rata-rata tertinggi terdapat pada pernyataan "Saya menyelesaikan pekerjaan dengan tepat waktu". Nilai rata-rata terendah terdapat pada pernyataan "Saya sangat optimal menggunakan jam kerja".

Tabel 13.

Hasil Uji Normalitas Struktur 1

\begin{tabular}{lc}
\hline & Unstandardized Residual \\
\hline $\mathrm{N}$ & 42 \\
Test Statistics & 0,102 \\
Asymp. Sig. (2-tailed) & 0,200 \\
\hline
\end{tabular}

Sumber : Data Primer diolah, 2019

Berdasarkan Tabel 4. dapat dilihat bahwa nilai Asymp. Sig. (2-tailed) sebesar 0,200, hasil tersebut mengindikasikan bahwa model persamaan regresi tersebut berdistribusi normal karena nilai Asymp. Sig. (2-tailed) lebih besar dari nilai alpha 0,05 .

Tabel 14.

Hasil Uji Normalitas Struktur 2

\begin{tabular}{lc}
\hline & Unstandardized Residual \\
\hline $\mathrm{N}$ & 42 \\
Test Statistics & 0,125 \\
Asymp. Sig. (2-tailed) & 0,098 \\
\hline
\end{tabular}

Sumber : Data Primer diolah, 2019

Berdasarkan Tabel 14. dapat dilihat bahwa nilai Asymp. Sig. (2-tailed) sebesar 0,125 , hasil tersebut mengindikasikan bahwa model persamaan regresi tersebut berdistribusi normal karena nilai Asymp. Sig. (2-tailed) lebih besar dari nilai alpha 0,05 .

Tabel 15.

Hasil Uji Multikoleniaritas

\begin{tabular}{llcc}
\hline \multicolumn{1}{c}{ Persamaan Struktur } & \multicolumn{1}{c}{ Variabel } & Tolerance & VIF \\
\hline $\mathrm{M}=\beta_{1} \mathrm{X}+\mathrm{e}_{1}$ & Stress Kerja $(\mathrm{X})$ & 1,000 & 1,000 \\
$\mathrm{Y}=\beta_{1} \mathrm{X}+\beta_{2} \mathrm{M}+\mathrm{e}_{2}$ & Stresss Kerja $(\mathrm{X})$ & 0,479 & 2,088 \\
& Kepuasan Kerja $(\mathrm{M})$ & 0,479 & 2,088 \\
\hline
\end{tabular}

Sumber: Data Primer diolah, 2019

Berdasarkan Tabel 15. dapat dilihat bahwa nilai tolerance dan VIF dari variabel stresss kerja dan kepuasan kerja menunjukkan nilai tolerance untuk setiap variabel lebih besar dari 0,1 dan nilai VIF lebih kecil dari 10 yang berarti model persamaan regresi bebas dari multikolinearitas.

Pada Tabel 16. dapat dilihat bahwa nilai signifikansi dari variabel Stress Kerja sebesar 0,083. Nilai tersebut lebih besar dari 0,05 yang berarti tidak terdapat pengaruh antara variabel bebas terhadap absolute residual. Dengan demikian, model yang dibuat tidak mengandung gejala heteroskedastisitas. 
Tabel 16.

Hasil Uji Heteroskedastisitas Struktur 1

\begin{tabular}{llrrrrr}
\hline \multirow{2}{*}{ Model } & \multicolumn{2}{c}{$\begin{array}{c}\text { Unstandardized } \\
\text { Coefficients }\end{array}$} & $\begin{array}{c}\text { Standardized } \\
\text { Coefficients }\end{array}$ & \multirow{2}{*}{ t } & \multirow{2}{*}{ Sig. } \\
\cline { 2 - 4 } & \multicolumn{1}{c}{ B } & Std. Error & \multicolumn{1}{c}{ Beta } & & \\
\hline 1 & (Constant) & 4.315 & 1.154 & & 3.738 & .001 \\
& Stress Kerja & -.082 & .046 & -.271 & -1.777 & .083
\end{tabular}

a. Dependent Variable: ABS_RES1

Sumber: Data Primer diolah, 2019

Tabel 17.

Hasil Uji Heteroskedastisitas Struktur 2

\begin{tabular}{llrrrrr}
\hline \multirow{2}{*}{ Model } & \multicolumn{2}{c}{$\begin{array}{c}\text { Unstandardized } \\
\text { Coefficients }\end{array}$} & $\begin{array}{c}\text { Standardized } \\
\text { Coefficients }\end{array}$ & \multicolumn{1}{c}{ t } & \multirow{2}{*}{ Sig. } \\
\cline { 3 - 5 } & & \multicolumn{1}{c}{ B } & \multicolumn{1}{c}{ Std. Error } & \multicolumn{1}{c}{ Beta } & & \\
\hline 1 & (Constant) & .381 & 1.686 & & .226 & .822 \\
& Stress Kerja & .047 & .038 & .271 & 1.236 & .224 \\
& Kepuasan Kerja & -.012 & .048 & -.057 & -.258 & .798
\end{tabular}

a. Dependent Variable: ABS_RES2

Sumber : Data Primer diolah, 2019

Pada Tabel 17. dapat dilihat bahwa nilai signifikansi dari variabel Stress Kerja dan kepuasan kerja, masing-masing sebesar 0,224 dan 0,798. Nilai tersebut lebih besar dari 0,05 yang berarti tidak terdapat pengaruh antara variabel bebas terhadap absolute residual. Dengan demikian, model yang dibuat tidak mengandung gejala heteroskedastisitas.

Perhitungan koefisien path dilakukan dengan analisis regresi melalui software SPSS 24.0 for Windows, diperoleh hasil yang ditunjukan pada Tabel 18 . berikut.

Tabel 18.

Hasil Analisis Jalur 1

\begin{tabular}{llrrrr}
\hline Model & \multicolumn{2}{c}{$\begin{array}{c}\text { Unstandardized } \\
\text { Coefficients }\end{array}$} & $\begin{array}{c}\text { Standardized } \\
\text { Coefficients } \\
\text { Beta }\end{array}$ & t & Sig. \\
& \multicolumn{1}{c}{ B } & Std. Error & \multicolumn{1}{c}{. } & \\
\hline $1 \quad$ (Constant) & 32.411 & 2.175 & & 14.903 & .000 \\
$\quad$ Stress Kerja & -.573 & .087 & -.722 & -6.596 & .000 \\
\hline R Square & 0,521 & & & & \\
F Statistik & 43,514 & & & & \\
Sig. Uji F & 0,000 & & & &
\end{tabular}

Berdasarkan hasil analisis jalur substruktur 1 seperti yang disajikan pada Tabel 18. maka dapat dibuat persamaan struktural sebagai berikut:

$$
\begin{aligned}
& \mathrm{M}=\alpha+\beta_{1} \mathrm{X}+\varepsilon_{1} \\
& \mathrm{M}=32,411-0,722 \mathrm{X}+0,087
\end{aligned}
$$

Nilai koefisien regresi variabel orientasi pasar bernilai positif dengan nilai signifikansi uji t kurang dari 0,05 . Hal ini menunjukkan bahwa variabel 
stress kerja memiliki pengaruh negatif yang signifikan terhadap variabel kepuasan kerja. Besarnya pengaruh variabel bebas terhadap variabel terikat yang ditunjukkan oleh nilai determinasi total (R Square) sebesar 0,521 mempunyai arti bahwa sebesar 52,1\% variasi kepuasan kerja dipengaruhi oleh variasi stresss kerja sedangkan sisanya sebesar $35,3 \%$ dijelaskan oleh faktor lain yang tidak dimasukkan ke dalam model.

Tabel 19.

Hasil Analisis Jalur 2

\begin{tabular}{|c|c|c|c|c|c|}
\hline \multirow[t]{2}{*}{ Variabel } & \multicolumn{2}{|c|}{$\begin{array}{c}\text { Unstandardized } \\
\text { Coefficients }\end{array}$} & \multirow{2}{*}{$\begin{array}{c}\text { Standardized } \\
\text { Coefficients } \\
\text { Beta } \\
\end{array}$} & \multirow[t]{2}{*}{ t hitung } & \multirow{2}{*}{$\underset{t}{\text { Sig. uji }}$} \\
\hline & B & Std. Error & & & \\
\hline (Constant) & 20.192 & 3.202 & & 6.306 & .069 \\
\hline Stress Kerja (X) & -.270 & .072 & -.306 & -3.736 & .001 \\
\hline Kepuasan Kerja (M) & .766 & .091 & .690 & 8.426 & .000 \\
\hline R Square & 0,935 & & & & \\
\hline F Statistik & 136,126 & & & & \\
\hline Signifikansi Uji F & 0,000 & & & & \\
\hline
\end{tabular}

Berdasarkan hasil analisis jalur substruktur 2 seperti yang disajikan pada Tabel 19. maka dapat dibuat persamaan struktural sebagai berikut:

$$
\begin{aligned}
& Y=\alpha+\beta_{2} X+\beta_{3} M+\varepsilon_{2} \\
& Y=20,192-0,306 X+0,690 M+0,091
\end{aligned}
$$

Nilai koefisien regresi masing-masing variabel bebas bernilai positif dengan nilai signifikansi uji t kurang dari 0,05 . Hal ini menunjukkan bahwa semua variabel bebas memiliki pengaruh positif yang signifikan terhadap variabel terikat. Besarnya pengaruh variabel bebas terhadap variabel terikat yang ditunjukkan oleh nilai determinasi total (R Square) sebesar 0,935 mempunyai arti bahwa sebesar 93,5\% variasi Kinerja Karyawan dipengaruhi oleh variasi stresss kerja dan kepuasan kerja, sedangkan sisanya sebesar 6,5\% dijelaskan oleh faktor lain yang tidak dimasukkan ke dalam model.

Berdasarkan model substruktur 1 dan substruktur 2, maka dapat disusun model diagram jalur akhir. Perhitungan pengaruh error (Pei), mendapatkan hasil pengaruh error $\left(\mathrm{P} \varepsilon_{1}\right)$ sebesar 0,692 dan pengaruh error $\left(\mathrm{P} \varepsilon_{2}\right)$ sebesar 0,255 . Hasil koefisien determinasi total adalah sebagai berikut :

$$
\begin{aligned}
\mathrm{R}^{2} \mathrm{~m} & =1-\left(\mathrm{P} \varepsilon_{1}\right)^{2}\left(\mathrm{P} \varepsilon_{2}\right)^{2} \\
& =1-(0,692)^{2}(0,255)^{2} \\
& =1-(0,478)(0,065) \\
& =1-0,031=0,969
\end{aligned}
$$

Nilai determinasi total sebesar 0,969 mempunyai arti bahwa sebesar 96,9\% variasi Kinerja Karyawan dipengaruhi oleh variasi Stress Kerja dan kepuasan kerja, sedangkan sisanya sebesar 3,1\% djelaskan oleh faktor lain yang tidak dimasukkan ke dalam model. Berdasarkan hasil analisis pengaruh stress kerja terhadap Kinerja Karyawan diperoleh nilai Signifikansi sebesar 0,001 dengan nilai koefisien beta $-0,306$ bernilai negatif. Nilai Signifikansi $0,001<0,05$ 
mengindikasikan bahwa $\mathrm{H}_{0}$ ditolak dan $\mathrm{H}_{2}$ diterima. Hasil ini mempunyai arti bahwa Stress Kerja berpengaruh negatif terhadap Kinerja Karyawan.

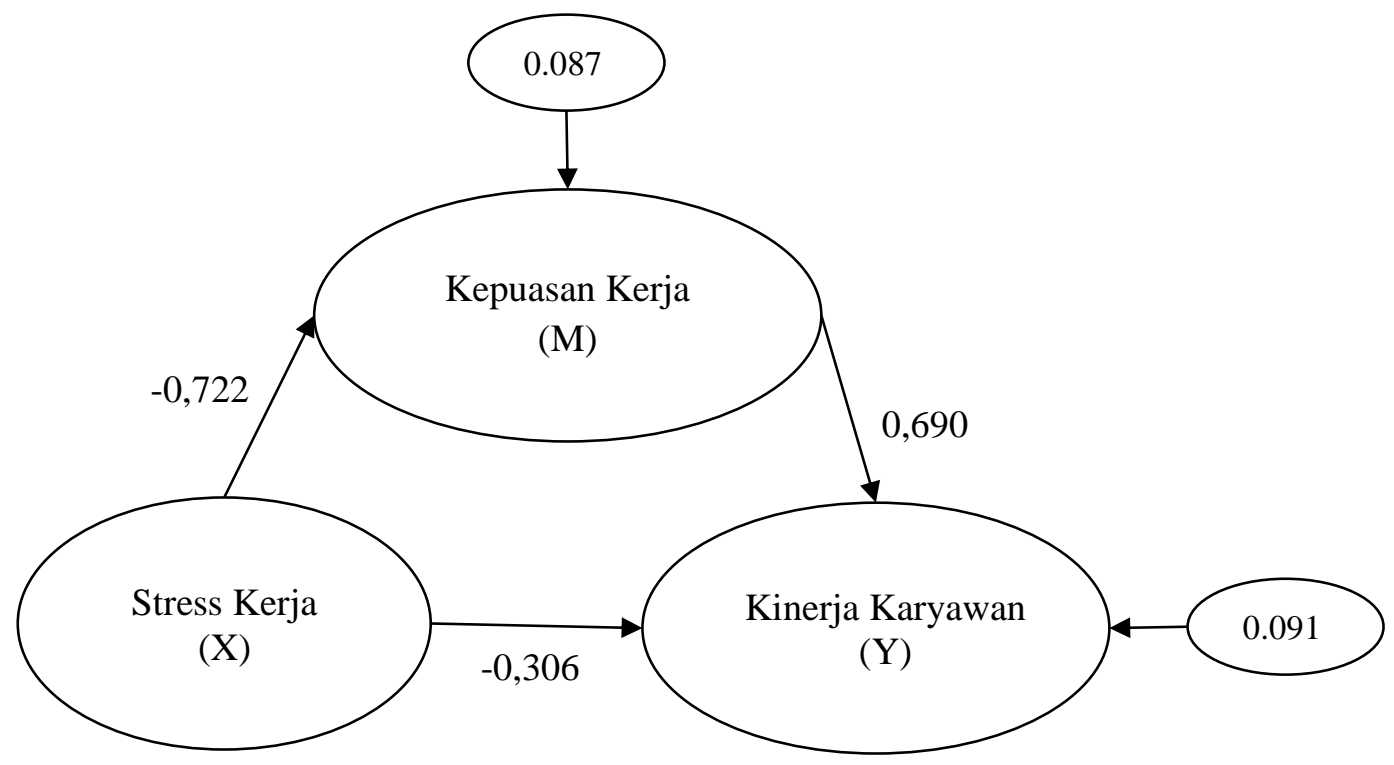

\section{Gambar 1. Validasi Model Diagram Jalur Akhir}

Sumber : Data Primer diolah, 2019

Berdasarkan diagram jalur pada Gambar 1. maka dapat dihitung besarnya pengaruh langsung dan pengaruh tidak langsung serta pengaruh total antar variabel. Perhitungan pengaruh antar variabel dirangkum dalam Tabel 20. sebagai berikut.

Tabel 20.

\section{Pengaruh Langsung dan Pengaruh Tidak Langsung serta Pengaruh Total} Stress Kerja (X), Kepuasan Kerja (M), dan Kinerja Karyawan (Y)

\begin{tabular}{cccc}
\hline $\begin{array}{c}\text { Pengaruh } \\
\text { Variabel }\end{array}$ & $\begin{array}{c}\text { Pengaruh } \\
\text { Langsung }\end{array}$ & $\begin{array}{c}\text { Pengaruh Tidak Langsung Melalui } \\
\text { Perceived Value } \\
(\mathbf{Y 1})(\boldsymbol{\beta 1} \mathbf{x} \boldsymbol{\beta 3})\end{array}$ & Pengaruh Total \\
\hline $\mathrm{X} \rightarrow \mathrm{M}$ & $-0,722$ & - & $-0,722$ \\
$\mathrm{X} \rightarrow \mathrm{Y}$ & $-0,306$ & $-0,498$ & $-0,804$ \\
$\mathrm{M} \rightarrow \mathrm{Y}$ & 0,690 & - & 0,690 \\
\hline Sumber
\end{tabular}

Tabel 20. menunjukkan bahwa pengaruh langsung Stress Kerja terhadap kepuasan kerja adalah sebesar -0,722. Pengaruh langsung variabel stresss kerja terhadap Kinerja Karyawan sebesar -0,306. Pengaruh langsung variabel kepuasan kerja terhadap Kinerja Karyawan sebesar 0,690. Hal ini berarti bahwa variabel Kinerja Karyawan lebih besar dipengaruhi oleh kepuasan kerja dari stresss kerja. Sedangkan pengaruh tidak langsung variabel stresss kerja terhadap Kinerja Karyawan melalui kepuasan kerja sebesar -0,498. Jadi pengaruh total variabel stresss kerja terhadap Kinerja Karyawan melalui kepuasan kerja adalah sebesar 0,804 Jadi dapat disimpulkan bahwa lebih besar total pengaruh stresss kerja 
terhadap Kinerja Karyawan yang melalui kepuasan kerja, daripada pengaruh langsung Stress Kerja terhadap Kinerja Karyawan tanpa melalui variable kepuasan kerja. Uji Sobel menunjukkan Z hitung sebesar -5,46 > 1,96. Artinya kepuasan kerja menjadi mediasi pada hubungan Stress Kerja terhadap Kinerja Karyawan. Nilai VAF (53,3 persen) lebih dari 20 persen, maka dapat dijelaskan bahwa ada efek mediasi atau dengan kata lain kepuasan kerja sebagai pemediasi parsial (partial mediation).

Hasil pemeriksaan uji mediasi telah menunjukkan bahwa sesuai dengan kriteria pengaruh variabel eksogen terhadap variabel mediasi $(0,000<0,05)$ adalah signifikan, pengaruh variabel mediasi terhadap varibel endogen $(0,000<$ $0,05)$ adalah signifikan, pengaruh langsung variabel eksogen terhadap variabel endogen pada model dengan melibatkan variabel mediasi $(0,000<0,05)$ adalah signifikan, maka dapat dikatakan sebagai partial mediation. Dengan demikian, kepuasan kerja sebagai partial mediation antara pengaruh Stress Kerja terhadap Kinerja Karyawan, maka hipotesis 4, yang menyatakan bahwa kepuasan kerja mampu memediasi pengaruh Stress Kerja terhadap Kinerja Karyawan diterima.

Berdasarkan hasil analisis pengaruh stresss kerja terhadap Kinerja Karyawan diperoleh nilai Signifikansi sebesar 0,001 dengan nilai koefisien beta 0,306 bernilai negatif. Nilai Signifikansi $0,001<0,05$ mengindikasikan bahwa $\mathrm{H}_{0}$ ditolak dan $\mathrm{H}_{2}$ diterima. Hasil ini mempunyai arti bahwa Stress Kerja berpengaruh negatif terhadap Kinerja Karyawan. Hal ini menandakan semakin tinggi nilai stresss kerja maka kepuasan kerja dari pegawai akan menurun.

Stress individu sangat mempengaruhi organisasi dalam mencapai tujuannya. Stress individu mungkin yang paling berpengaruh terhadap semua stresssor yang ada karena merupakan perubahan yang tak pernah berhenti, dan merupakan bagian dari kehidupan saat ini. Purbaningrat Yo \& Surya (2015) stress kerja merupakan masalah serius yang berhubungan dengan kepuasan kerja, hal ini dibuktikan dengan penelitian yang telah dilakukan memperoleh hasil bahwa stress kerja berpengaruh negatif terhadap kepuasan kerja. Hal ini didukung juga oleh penelitian yang dilakukan Redita \& Dewi (2019) menemukan stresss kerja berpengaruh terhadap kepuasan kerja, didukung oleh penelitian yang dilakukan Prawira \& Suwandana (2019) yang menemukan stresss kerja memiliki pengaruh negatif terhadap kepuasan kerja. Penelitian yang dilakukan oleh Singh dan Nayak (2017) kepada polisi di India menemukan bahwa stresss kerja berpengaruh secara signifikan terhadap kepuasan kerja.

Berdasarkan hasil analisis pengaruh stresss kerja terhadap kepuasan kerja diperoleh nilai Signifikansi sebesar 0,000 dengan nilai koefisien beta $-0,722$ bernilai negatif. Nilai Signifikansi $0,000<0,05$ mengindikasikan bahwa $\mathrm{H}_{0}$ ditolak dan $\mathrm{H}_{1}$ diterima. Hasil ini mempunyai arti bahwa stress kerja berpengaruh negatif terhadap kepuasan kerja. Semakin tinggi tingkat stress kerja maka tingkat Kinerja Karyawan pegawai juga akan semakin menurun begitu sebaliknya.

Hasil penelitian Wijaya \& Sudibya (2014) menyatakan bahwa stress kerja berpengaruh negatif signifikan terhadap kinerja karyawan, karena beban kerja yang berlebihan, pengembangan karier, masalah keluarga dan masalah organisasi dapat menurunkan kinerja karyawan tersebut dimana karyawan merasa capek, gelisah, tidak bahagia, sakit kepala, lemah serta mudah marah. Prawira \& 
Suwandana (2019) juga mengungkap terdapat hubungan negatif signifikan antara variabel stress kerja dan kinerja karyawan. Namun penelitian tersebut bertolak belakang dengan penelitian dilakukan oleh Zafar et al. (2015) yang menyebutkan bahwa stress kerja berpengaruh positif terhadap kinerja karyawan. Diputra \& Surya (2018) menunjukan bahwa stress kerja berpengaruh negatif dan signifikan terhadap kepuasan kerja dan kinerja karyawan. Hal ini berarti karyawan yang tingkat stressnya rendah akan memiliki kinerja yang lebih tinggi dibandingkan dengan karyawan yang memiliki tingkat stress yang lebih tinggi.

Berdasarkan hasil analisis pengaruh kepuasan kerja terhadap Kinerja Karyawan diperoleh nilai Signifikansi sebesar 0,000 dengan nilai koefisien beta 0,690 bernilai positif. Nilai Signifikansi $0,000<0,05$ mengindikasikan bahwa $\mathrm{H}_{0}$ ditolak dan $\mathrm{H}_{3}$ diterima. Hasil ini mempunyai arti bahwa kepuasan kerja berpengaruh positif terhadap Kinerja Karyawan. Hasil ini mempunyai arti bahwa kepuasan kerja berpengaruh positif terhadap Kinerja Karyawan.

Penelitian dari Hermawan \& Suwandana (2019) menyatakan bahwa kepuasan berpengaruh positif terhadap kinerja karyawan. Zafar et al. (2015) menunjukan kepuasan kerja berpengaruh terhadap kinerja. Hal ini berpengaruh secara langsung, namun memiliki hubungan yang signifikan akan karena hasil riset menunjukan hasil positif. Diputra \& Surya (2018) menyatakan bahwa kepuasan kerja memberikan pengaruh terhadap kinerja karyawan yang signifikan. Ini mengindikasikan bahwa kepuasan kerja mampu memberi kontribusi kepada peningkatan kinerja karyawan. Prawira \& Suwandana (2019) juga mengungkapkan bahwa kepuasan kerja secara signifikan memiliki hubungan dengan kinerja karyawan. Beberapa penelitian mengemukakan bahwa kepuasan kerja memiliki pengaruh positif dan signifikan terhadap kinerja karyawan yang berarti bahwa rasa kepuasan kerja yang dimiliki pekerja membuat pekerja untuk meningkatkan kinerjanya.

Berdasarkan hasil analisis data didapat nilai Z hitung sebesar -5,33 > 1,96. Artinya Kepuasan kerja mediasi hubungan antara Stress Kerja terhadap Kinerja Karyawan. Selain itu, nilai VAF sebesar 53,3\% yaitu lebih dari 20\%, maka dapat dijelaskan bahwa ada efek mediasi atau dengan kata lain kepuasan kerja sebagai pemediasi parsial (partial mediation).

Berdasarkan hasil penelitian Diputra \& Surya (2018) didapatkan hasil bahwa kepuasan kerja berpengaruh positif antara variabel stresss kerja terhadap kinerja karyawan melalui variabel kepuasan kerja. Prawira \& Suwandana (2019) menyatakan bahwa terdapat hasil kepuasan kerja sebagai pemediasi antara stress kerja terhadap kinerja karyawan. Adawiyah (2015) menemukan bahwa kepuasan kerja berpengaruh positif dan signifikan dalam memediasi stress kerja terhadap kinerja karyawan.

Implikasi teoritis dari hasil penelitian ini memberikan bukti pada pengembangan ilmu perilaku keorganisasian dan sumber daya manusia khususnya mengenai stress kerja, kinerja karyawan dan kepuasan kerja karyawan. Dengan demikian, hasil penelitian ini memberi dukungan empiris dan dapat dinyatakan memperkuat hasil-hasil studi terdahulu. Selain itu hasil penelitian ini secara praktis dapat menjadi salah satu acuan bagi peneliti lainnya yang ingin meneliti mengenai stress kerja, kepuasan kerja dan kinerja karyawan. Secara teoritis 
penelitian ini juga memberikan pemahaman bahwa stress kerja dan kepuasan kerja secara nyata dapat mempengaruhi kinerja karyawan. Ketika stress kerja yang dirasakan karyawan rendah maka dapat meningkatkan kepuasan kerja, sehingga kinerja karyawan akan semakin meningkat.

Keterbatasan dalam penelitian ini antara lain banyaknya prosedur birokrasi yang harus dilewati peneliti agar dapat melakukan penelitian di tempat ini dan informasi yang diberikan oleh pimpinan kurang lengkap sehingga peneliti harus terus mengingatkan pimpinan perusahaan. Objek penelitian yang memiliki ruanglingkup yang terbatas yakni hanya sebatas koperasi membuat hasil penelitian kurang sesuai untuk diterapkan pada objek atau perusahaan besar karena secara struktur organisasi pun sudah berbeda serta penerapan pemecahan masalah pun juga berbeda.

\section{SIMPULAN}

Stress Kerja berpengaruh negatif terhadap kepuasan kerja di Koperasi Graha Canti. Hal ini menunjukan bahwa jika Stress Kerja di Koperasi Graha Canti semakin meningkat maka kepuasan kerja di Koperasi Graha Canti akan menurun. Stress Kerja berpengaruh negatif terhadap Kinerja Karyawan di Koperasi Graha Canti. Hal ini menunjukan bahwa jika Stress Kerja di Koperasi Graha Canti semakin meningkat maka Kinerja Karyawan di Koperasi Graha Canti akan menurun. Kepuasan kerja berpengaruh positif dan signifikan terhadap Kinerja Karyawan di Koperasi Graha Canti. Hal ini menunjukan bahwa jika kepuasan kerja di Koperasi Graha Canti semakin meningkat maka akan meningkatkan pula Kinerja Karyawan di Koperasi Graha Canti. Kepuasan kerja memediasi stresss kerja terhadap kinerja karyawan di Koperasi Graha Canti. Hal ini menunjukan bahwa stress kerja di Koperasi Graha Canti memberikan dampak yang signifikan terhadap Kinerja Karyawan di Koperasi Graha Canti jika di mediasi oleh kepuasan kerja di Koperasi Graha Canti, yang berarti bahwa Kinerja Karyawan di Koperasi Graha Canti sangat tergantung pada tingkat kepuasan kerja di Koperasi

Graha Canti tersebut dan juga tingkat Stress Kerja di Koperasi Graha Canti. Untuk mengurangi stress kerja karyawan manajemen Koperasi Graha Canti hendaknya menghindari berbagai bentuk perubahan sistem yang baru secara tibatiba dan menghindari terjadinya konflik antar kelompok di dalam perusahaan sehingga karyawan tidak akan merasa takut atau tertekan saat bekerja. Untuk meningkatkan kepuasan kerja karyawan hendaknya pimpinan selalu membantu dan memberi petunjuk mengenai kegiatan sehari-hari sehingga menimbulkan rasa puas dalam diri karyawan. Untuk meningkatkan kinerja karyawan hendaknya para karyawan menggunakan jam kerja secara optimal sehingga mampu bekerja dengan kualitas sesuai target yang ditetapkan dan menyelesaikan pekerjaan dengan tepat waktu. Bagi peneliti selanjutnya, diharapkan untuk melakukan penelitian dengan cakupan yang lebih luas seperti menambahkan variabel lain diluar penelitian ini dan melakukan penelitian pada sektor lain. 


\section{REFERENSI}

Adawiyah, K. (2015). Pengaruh Keadilan Distributif Kompensasi dan Gaya Kepemimpinan Transfoemasional terhadap Komitmen Afektif Karyawan JNE Banten dengan Kepuasan Kerja sebagai Variabel Interving. Muhammadiyah Yogyakarta.

Alshitri, K. (2013). An Investigation of Factors Affecting Job Satisfaction among R\&D Center Employees in Saudi Arabia. The Journal of Human Resources Management Research. https://doi.org/10.5171/2013.279369

Blau, P. M. (2017). Exchange and power in social life. Exchange and Power in Social Life. https://doi.org/10.4324/9780203792643

Cahyono, H. D. (2014). Pengaruh Lingkungan Kerja, Konflik Kerja, Stress Kerja, Serta Kepemimpinan Terhadap Kinerja Karyawan di PT. Telkom Indonesia, Tbk Area Denpasar. Buletin Studi Ekonomi, 19(1), 1-117. Retrieved from http://www.accorhotels-group.com/en/franchise-and-management/10reasons-to-join-accorhotels/powerful-distribution-and-revenuemanagement.html

Chandio, J. A., Jhatial, A. A., \& Mallah, R. (2013). Modeling The Relationship Of Uncelar Career Developmen With Job Dissatisfaction, Job Sress and Employees Turnover Intention: Sructural Equation Modeling Approach. Journal of Arts Humamanities, 41(41), 55-57.

Dewi, K., \& Wibawa, I. (2016). Pengaruh Stres Kerja Pada Turnover Intention Yang Dimediasi Kepuasan Kerja Agen AJB Bumiputera 1912. E-Jurnal Manajemen Universitas Udayana.

Diputra, A. A. D. P., \& Surya, I. B. K. (2018). Pengaruh Stres Kerja Terhadap Kinerja Karyawan Dimediasi Oleh Kepuasan Kerja Karyawan PT. Destination Asia Bali. E-Jurnal Manajemen Universitas Udayana. https://doi.org/10.24843/ejmunud.2019.v08.i02.p16

Hermawan, A. A. D., \& Suwandana, I. G. M. (2019). Peran Kepuasan Kerja Memediasi Komunikasi Terhadap Kinerja Karyawan. E-Jurnal Manajemen Universitas Udayana. https://doi.org/10.24843/ejmunud.2019.v08.i07.p17

Huda, K. (2018). Pengaruh Kepuasan Kerja Terhadap Organizational Citizenship Behavior (OCB) Komitmen Organisasi Sebagai Variabel Intervening (Studi Kasus Pada Pt Citayasah Perdana). Optima, 2(1), 41. https://doi.org/10.33366/opt.v2i1.900

Kasim, A. (2016). Applied Biclustering Methods for Big and High-Dimensional Data Using R. Applied Biclustering Methods for Big and High-Dimensional Data Using R. https://doi.org/10.1201/9781315373966

Kouloubandi, A. (2012). Analysis The Relationship Between Job Stresss, Intrisic Motivation and Employes Creativity in Islamic Republic of Iran Railways 
Organization. Interdiscipplinary. Journal of Contemporary Researah in Business, 4(8), 39-53.

Manurung dan Ratnawati. (2012). Analisis Pengaruh Stres Kerja Dan Kepuasan Kerja Terhadap Turnover Intention Karyawan ( Studi Pada STIKES Widya Husada Semarang ), 1, 1-13.

Nawaz, M. S., Hassan, M., Hassan, S., Shaukat, S., \& Asadullah, M. A. (2014). Impact of employee training and empowerment on employee creativity through employee engagement: Empirical evidence from the manufacturing sector of Pakistan. Middle - East Journal of Scientific Research. https://doi.org/10.5829/idosi.mejsr.2014.19.4.13618

Prawira, I. G. A. G. Y., \& Suwandana, I. G. M. (2019). Peran Kepuasan Kerja Memediasi Pengaruh Stres Kerja Terhadap Kinerja Karyawan Housekeeping Department Fave Hotel. E-Jurnal Manajemen Universitas Udayana. https://doi.org/10.24843/ejmunud.2019.v08.i08.p13

Purbaningrat Yo, P., \& Surya, I. (2015). Pengaruh Beban Kerja Terhadap Kepuasan Kerja Dengan Stres Kerja Sebagai Variabel Mediasi. E-Jurnal Manajemen Universitas Udayana.

Redita, Y. I. G., \& Dewi, S. K. (2019). Pengaruh Stress Kerja Terhadap Kepuasan Kerja Dengan Motivasi Kerja Sebagai Variabel Mediasi. E-Jurnal Manajemen Unud, 8(3).

Rivai, V. (2005). Manajemen Sumber Daya Manusia Untuk Perusahaan: dari Teori ke Praktik. Edisi Pertama, Penerbit PT. Raja Grafindo Persada, Jakarta. https://doi.org/10.1371/journal.pone.0013666

Robbins, S. P., \& Judge, T. . (2011). Perilaku Organisasi (12th ed.). Jakarta: Salemba Empat.

Serim, H., Demirbağ, O., \& Yozgat, U. (2014). The Effects of Employees' Perceptions of Competency Models on Employability Outcomes and Organizational Citizenship Behavior and the Moderating Role of Social Exchange in this Effect. Procedia - Social and Behavioral Sciences. https://doi.org/10.1016/j.sbspro.2014.09.125

Singh dan Nayak. (2017). Mediating role of stress between work-family conflict and job satisfaction among the police officials Policing: An International Journal of Police Strategies \& Management Article information :, (November 2015). https://doi.org/10.1108/PIJPSM-03-2015-0040

Sri, R., \& Karini, R. A. (2015). Stress Role and Dysfunctional Behavior on The Performance of Internal Auditor. Journal of Trikonomika, 14(2), 129-137.

Wijaya, \& Sudibya. (2014). Pengaruh Stress Kerja, Lingkungan Kerja Fisik dan Kompensasi Finansial Terhadap Kinerja Karyawan. E-Jurnal Manajemen 
I Wayan Bayu Sandiartha, Pengaruh Stres Kerja...

Unud., 3(11). https://doi.org/http://dx.doi.org/10.2307/1556364

Yuen, D. C. Y., Law, P. K. F., Lu, C., \& Guan, J. Q. (2013). Dysfunctional auditing behaviour: Empirical evidence on auditors' behaviour in Macau. International Journal of Accounting and Information Management. https://doi.org/10.1108/IJAIM-12-2012-0075

Zafar, Q., Ali, A., Hameed, T., Ilyas, T., \& Younas, H. I. (2015). Influence of Job Stresss on Employees Performance in Pakistan. American Journal of Social Science Research, 1(4), 221-225. https://doi.org/https://doi.org/10.5121/ijfcst.2014.4403 